\title{
LOS OTROS EN NOSOTROS Y LA GRAMÁTICA DE LA PRIMERA PERSONA DEL PLURAL
}

Juan Antonio González de Requena Farré

\section{(9) $(1) \Theta \Theta$}

Doi: https://doi.org/10.15517/rfl.v46i1.41116

URL: https://revistas.ucr.ac.cr/index.php/filyling/index 



\title{
LOS OTROS EN NOSOTROS Y LA GRAMÁTICA DE LA PRIMERA PERSONA DEL PLURAL
}

\author{
THE OTHERS IN NOSOTROS AND THE GRAMMAR \\ OF THE FIRST PERSON PLURAL
}

\author{
Juan Antonio González de Requena Farré
}

\begin{abstract}
RESUMEN
El pronombre nosotros y la primera persona del plural han generado interés no solo en las ciencias del lenguaje, sino también en filosofía y ciencias sociales, ya que cumplen importantes funciones en la subjetivación discursiva y en la identificación colectiva. En esta revisión sistemática se examinan distintas propuestas de clasificación de los valores referenciales y funciones discursivas del nosotros (sin distinguir el uso expreso del pronombre y la forma gramatical de la primera persona del plural); además, se presentan los empleos paradigmáticos en el discurso coloquial, mediático, político y académico. Finalmente, se propone una ordenación y modelización de los principales empleos del nosotros y de la primera persona del plural. La sistematización propuesta en este artículo suministra una articulación de los valores referenciales y las funciones discursivas con los diferentes tipos de enmarcado cognitivo y conceptualizaciones de la escena discursiva.

Palabras clave: primera persona del plural; deixis personal; subjetivación discursiva; identificación colectiva; enmarcado cognitivo.
\end{abstract}

\begin{abstract}
The pronoun nosotros and the first person plural have generated interest not only in the sciences of the language, but also in philosophy and social sciences, since they fulfill important functions in the discursive subjectivation and in the collective identification. In this systematic review different proposals of classification of referential values and discursive functions of nosotros are examined (without distinguishing the express use of the pronoun and the grammatical form of first person plural); in addition, paradigmatic uses of the pronoun and the first person plural in colloquial, media, political and academic discourse are presented. Finally, we propose an organization and modeling of the main uses of nosotros and the first person plural. The systematization proposed in this article provides an articulation of the referential values and discursive functions with the different types of cognitive framing and conceptualizations of the discursive scene.

Keywords: first person plural; personal deixis; discursive subjectivity; collective identification; cognitive framing.
\end{abstract}

Dr. Juan Antonio González de Requena Farré. Profesor asociado del Instituto de Psicología, Universidad Austral de Chile. Los Ríos, Chile.

Correo electrónico: jgonzalez@spm.uach.cl

Recepción: 22- 12- 18

Aceptación: 12- 04- 19 


\section{Introducción: nosotros y la identificación colectiva}

En el pensamiento contemporáneo, los pronombres personales han concitado un notorio interés a la hora de dar cuenta de las formas de subjetivación asociadas a la participación en el discurso. En ese orden de ideas, Rom Harré (1982) ha apelado al poder de los pronombres para conformar las identidades culturales, modular el tenor de nuestra vida moral y permitir posicionamientos discursivos más o menos comprometidos o distanciados. Así, pronombres como el de primera persona hacen posible que se concrete situacionalmente la puesta en escena de la enunciación, de manera que quien dice yo se singulariza concretamente como un hablante encarnado, a la vez que se posiciona como agente con iniciativa en un orden moral local. Por su parte, el pronombre de primera persona del plural difumina esa doble indexicalidad (es decir, la instancia situacional y social del discurso), al invocar un ámbito espacio-temporal más incierto y una responsabilidad moral más indefinida respecto a cierta comunidad de pertenencia: quien dice nosotros puede presentarse simultáneamente como portavoz de un ámbito trascendente o autorizador y como integrante del conjunto inmanente de quienes son interpelados a actuar (Harré, 1982, pp. 235-236; 2014).

Además, mediante la distinción entre nosotros y ellos, podemos expresar cierto sentimiento de pertenencia, afiliación e inclusión social. A través de las indicaciones de proximidad o distancia, de la asociación a un nosotros y la disociación discursiva respecto a otros, forjamos y gestionamos la trama de nuestra identidad social, en la cual los otros pueden eventualmente incorporarse como parte del nosotros y participar en una relación dialógica. En esa medida, el pronombre nosotros indica un hablante colectivo, distinto de la invocación distanciada de ellos, y permite articular discursivamente diferentes relaciones de inclusión y exclusión, como marcador identitario al servicio de la orientación social, pero también funcional a la construcción ideológica de autodefiniciones grupales y posicionamientos antagónicos (Duszak, 2002, pp. 1-9). Desde una perspectiva pragmática, cognitiva y social, se ha denominado "clusividad" (clusivity) a esas formas de inclusión o exclusión codificadas lingüísticamente -entre las que se encuentra el pronombre nosotros-, que posibilitan la legitimación o deslegitimación, la autopresentación positiva o la representación negativa de los otros, así como el distanciamiento o la cercanía, particularmente en el discurso político (Wieczorek, 2013). Según ha argumentado Teun Van Dijk, a propósito del abordaje de la ideología en el análisis crítico del discurso:

\footnotetext{
[...] la definición de ideología en términos de un esquema complejo de categorías que definen las evaluaciones del grupo propio y sus propiedades (identidad, actividad, objetivos, normas, relaciones de grupo y recursos) sugiere que las personas solo adquieren ideologías cuando han aprendido qué significa ser miembro de un grupo. Esto es, de pensar en términos de "yo", deben aprender a pensar en términos de "nosotros" y "ellos", a distinguir diferencias de grupo, identificarse con el grupo, participar en sus actividades, compartir algunos de sus objetivos, sujetarse a sus normas, valores y reglas, haber participado en la interacción y el conflicto entre grupos, y habérseles dado (o negado) el acceso a recursos sociales (2006, p. 310).
}

Asimismo, -como ha sostenido el psicólogo James Pennebaker (2011)- los pronombres personales son un tipo de palabras que, aunque constituyen términos funcionales y no elementos léxicos con un contenido, ponen de manifiesto aspectos relevantes de la personalidad, del estilo de pensamiento, de los estados emocionales y de las formas de relación con los otros. En ese sentido, el empleo del pronombre yo se asocia a una focalización en sí mismo y a una mayor atención a las propias vivencias, involucra cierta implicación personal y apropiación de las experiencias; por eso, lo emplearían más frecuentemente las víctimas de un trauma 
que quienes lo simulan, más los subordinados que los líderes. En cuanto al pronombre de primera persona del plural, la enunciación del nosotros opera como un marcador de identidad cuyo empleo permitiría apreciar la armonía en las relaciones interpersonales, el sentido de pertenencia grupal y el nivel de compromiso en integrantes de organizaciones e instituciones. Aunque existe un tipo de nosotros incluyente y otro distanciado, la convivencia y conversación constante con otros, o bien los acontecimientos públicos y los desastres colectivos, hacen posible un desplazamiento hacia un tipo de discurso más enmarcado en el nosotros y capaz de expresar solidaridad grupal (Pennebaker, 2011, cap. 9).

\section{Nosotros en las ciencias del lenguaje}

Si enfrentamos el asunto desde la perspectiva de las ciencias del lenguaje, toda esta teorización sobre los rendimientos identitarios, relacionales e ideológicos de los pronombres personales nos enfrenta a una cuestión previa: ¿Hasta qué punto la gramática de los pronombres personales sustenta todas esas interpretaciones filosóficas, sociológicas y psicológicas?

En la lingüística contemporánea,cabe reconocer cierto predominiode las aproximaciones semántico-discursivas cuando se trata de dar cuenta de la gramática de los pronombres personales. Ya en 1924, Otto Jespersen llamaba la atención sobre los riesgos derivados de una caracterización semántico-discursiva de la categoría conceptual del pronombre (como un tipo de expresión significativa ocasional), sin especificar los aspectos formales y funcionales propios de la gramática de este tipo de palabra (Jespersen, 1975, pp. 84-85). No obstante, el propio Jespersen había incluido a los pronombres personales en una categoría conceptual de palabras cuyo significado cambia de acuerdo a la situación de enunciación: los shifters o conmutadores. Como término con una significación ocasional, el pronombre personal de primera persona realiza una genuina conmutación referencial cada vez que alguien toma la palabra y dice yo; sin embargo, según Jespersen, no se puede concluir que el empleo infantil del pronombre yo sea un signo de autoconciencia o de percepción diferenciada de sí mismo (Jespersen, 1922, p. 123). En lo que respecta al pronombre de primera persona del plural, Jespersen formuló interesantes observaciones sobre la presencia de un plural de aproximación: nosotros tiene una significación vaga e imprecisa, pues refiere tanto al yo del hablante como a uno o varios que no son ese yo. Según Jespersen, algunas lenguas presentan una distinción entre un nosotros inclusivo y un nosotros exclusivo, que no considera al oyente o interlocutor. Por ejemplo, en el español se introdujo la forma nosotros, en lugar de nos, cuando la expresión aparece aislada o se emplea enfáticamente (Jespersen, 1975, pp. 225-226).

Pese a las reservas de Jespersen, la caracterización lingüística de los pronombres personales se ha centrado recurrentemente en el aspecto semántico-discursivo y, concretamente, en la significación ocasional. De modo paradigmático, la Teoría del lenguaje de Karl Bühler (1979) asociaba los pronombres personales a cierto campo mostrativo del lenguaje y a las dimensiones deícticas del acontecimiento verbal concreto, que suministran recursos indicativos inherentes a la situación verbal y un sistema de orientación subjetiva centrado en el yo-aquíahora. Pese a no ser simples señales prelingüísticas e involucrar cierto aspecto simbólico, la significación de los términos deícticos solo se precisa en el acontecimiento verbal concreto; a diferencia de los recursos simbólicos del lenguaje, depende de la aprehensión tácita y de la orientación intuitiva en la situación verbal. Así, para Bühler, los pronombres personales yo y tú solo remiten a los actores circunstanciales de la acción verbal actual: yo designa a cualquier 
locutor eventual y permite individualizar a quien habla; tú remite, como una señal de apelación, a los receptores específicos. Ahora bien, aunque el sistema de orientación subjetiva que da forma a las coordenadas del campo mostrativo del lenguaje es eminentemente egocéntrico y se origina en el yo-aquí-ahora, Bühler argumenta que los recursos mostrativos pueden verse influidos por las circunstancias sociales, de manera que las ordenaciones sociales se expresen en los modos de mostración lingüística. Precisamente, el pronombre nosotros va más allá de la mera significación mostrativa, en la medida en que hace posible la formación de distintas clases, según se trate del nosotros inclusivo o del exclusivo (que no considera al receptor). Para Bühler, el pronombre nosotros no se limita a mostrar egocéntricamente, ya que también despliega una función de denominación y significación conceptual (Bühler, 1979, pp. 158-161).

De manera semejante, Roman Jakobson (1975) vinculó los pronombres personales a una particular modalidad de relación semántico-discursiva. Cuando Jakobson reflexionó sobre las modalidades de doble funcionamiento del mensaje y el código en la comunicación lingüística (en virtud de las cuales, por ejemplo, el mensaje implica una referencia al código, o este reenvía al mensaje), no solo consideró aquellos casos de circularidad en que el mensaje remite al mensaje por medio del discurso citado; o bien los nombres propios, en que el significado codificado se define solo por referencia al código. También contempló el caso de los solapamientos entre mensaje y código, ya sea mediante la autonimia, en que el mensaje remite al código al limitarse a mencionar formalmente la palabra (como en "Perro" tiene dos silabas), ya sea a través de aquellas unidades gramaticales en que el código no puede especificar el significado si no se hace referencia a la enunciación del mensaje. Pues bien, Jakobson recuperó el término conmutadores o embragues (shifters) para caracterizar la naturaleza semiótica de los términos en que se solapan la regulación codificada de un significado general y la referencia existencial al mensaje concreto en la elocución actual. El ejemplo más notorio de este tipo de solapamiento semántico-discursivo se da precisamente en los pronombres personales: por ejemplo, yo designa al emisor del mensaje, pero también individualiza a la persona singular que habla en cada ocasión, como si estuviéramos ante un particular tipo de símbolo-índice (Jakobson, 1975, pp. 307-311).

Entre las aproximaciones semántico-discursivas a los pronombres personales, quizá la de Émile Benveniste (1971) es la que con más fuerza ha insistido en el papel que estos cumplen en la constitución del sujeto del discurso y de la conciencia de sí. En la perspectiva de Benveniste, la instancia del discurso, esto es, el lenguaje actualizado intersubjetivamente, se realiza cada vez que el locutor se apropia de la lengua al decir yo y dirigirse como tú a su interlocutor (1971, pp. 179-187). En ese sentido, los pronombres personales no presentan un referente constante e idéntico, sino que serían indicadores autorreferenciales de la actual instancia de discurso; así, posibilitarían la conversión del lenguaje en discurso singular y la toma de conciencia del sujeto de la enunciación. El pronombre de primera persona solo designaría autorreferencialmente al locutor que actualiza la enunciación en cierta instancia del discurso que contiene la palabra yo; de modo análogo, el pronombre de segunda persona remite a aquel a quien se dirige la alocución. En el caso de la tercera persona, se da un modo de enunciación que no remite a la instancia de discurso, sino a algo otro e impersonal, de manera que se hace posible la referencia objetiva (Benveniste, 1971, pp. 172-178). En cuanto a la primera persona del plural, Benveniste observa que realmente no hay una pluralización o multiplicación de varios yo; más bien se da una vinculación entre yo y cierto no-yo, ya se trate de la unión de yo y vosotros, en el caso del nosotros inclusivo, o bien de la asociación 
de yo y ellos, en el nosotros exclusivo. Así pues, para Benveniste, el nosotros exclusivo vincula referentes con correlación de personalidad (persona y no-persona), mientras que el nosotros inclusivo remite a la correlación de subjetividad (yo y tú). En cuanto al nosotros de majestad o de autoría, tampoco se trata de una multiplicación del yo, sino que estaríamos ante una amplificación difusa de la primera persona, de modo que se expresa una comprensión más indefinida o una generalización vaga del yo (Benveniste, 1971, pp. 168-171).

También desde la perspectiva de una teoría de la enunciación, Catherine KerbratOrecchioni (1997) ha considerado el papel de los pronombres personales en la manifestación deíctica de la subjetividad en la situación de la comunicación y en el discurso. En todo caso, aunque existen marcas deícticas de la subjetividad en la enunciación (entre las cuales destaca el empleo del pronombre de primera persona), también habría huellas no deícticas de la presencia implícita del sujeto de la enunciación, como las marcas afectivas, interpretativas, evaluativas y axiológicas, o bien como la modalización del enunciado (que especifica la actitud epistémica del locutor, cuando dice creo que p, o estoy seguro de que p) e, incluso, la organización estilística del discurso. Respecto a esa huella deíctica de la subjetividad que son los pronombres personales, Kerbrat-Orecchioni introduce una matizada clasificación de las personas enunciativas, la cual se aleja de la propuesta de Benveniste en la medida en que cuestiona el carácter no significante o meramente autorreferencial de los pronombres personales, así como problematiza la condición de no-persona del pronombre de tercera persona. Kerbrat-Orecchioni no solo distingue varios tipos de personas involucradas en la interlocución (yo y tú) o ajenas a ella (tercera persona), sino que además introduce una diferencia entre diferentes tipos de locutores colectivos o nosotros: algunos consideran a los locutores y a los interlocutores (nosotros inclusivo); una segunda forma de la primera persona del plural comprende solo a los locutores y a terceros (nosotros exclusivo); finalmente, hay una tercera versión del nosotros que hace referencia a locutores, interlocutores y terceros. Asimismo, según Kerbrat-Orecchioni, cabría concebir un inagotable contenido referencial del pronombre de primera persona del plural, ya que el conjunto de los otros a que nosotros hace referencia siempre podría ampliarse con más de un interlocutor o con más de un tercero, ya sean ellos o ellas. En ese sentido, salvo en casos marginales de recitación colectiva, nosotros no correspondería a una pluralización del yo, sino a cierta referencia al locutor y a algún otro distinto del locutor (Kerbrat-Orecchioni, 1997, pp. 52-57).

El abordaje semántico-discursivo de los pronombres personales no se limita a la discusión sobre las formas de referencia y conmutación referencial asociadas a la deixis (esto es, a la indicación de los locutores y a la orientación verbal en la situación comunicativa concreta); también concierne a los patrones de interacción y las propuestas de vinculación interpersonal que se negocian en el discurso. En ese sentido, los pronombres personales han concitado el interés de la pragmática, en la medida en que ponen de manifiesto estrategias de posicionamiento de los interlocutores, así como modos de manipular la distancia personal y grupal en los procesos comunicativos (por ejemplo, mediante el tratamiento formal $\mathrm{u}$ honorífico, al decir usted en lugar de tú). A través de los pronombres personales se juegan distintas opciones para manejar la imagen pública con la cual los interlocutores se presentan ante los demás, y procuran el reconocimiento personal y la aprobación e inclusión sociales. Así pues, desde una perspectiva pragmática, podemos describir todo un repertorio de usos de los pronombres personales al servicio de la preservación de la relación social y de la cortesía comunicativa. 
Penelope Brown y Stephen C. Levinson (1987) dieron cuenta de un catálogo de estrategias universales tanto de cortesía positiva (mediante la afirmación de un trasfondo común, la oferta de cooperación y la invitación a la solidaridad) como de cortesía negativa (para evitar la intrusión y no afectar la autonomía del interlocutor). En este orden de ideas, el empleo de la primera persona del plural puede servir a una estrategia de cortesía positiva que remarque la pertenencia grupal y el vínculo interpersonal mediante el nosotros inclusivo, o bien involucre cierto desplazamiento en el posicionamiento personal, del yo al nosotros. Por ejemplo, según Brown y Levinson, las peticiones o solicitudes pueden realizarse con una formulación que enfatice la pertenencia grupal de los interlocutores, como ocurre en el empleo del nosotros inclusivo (es el caso del padre que dice a su hijo Tomémonos la medicina). Así, la fusión de los interlocutores bajo la forma del nosotros inclusivo expresa un desplazamiento en el centro personal de referencia, pese a que ese nosotros solo se refiere al oyente (Brown y Levinson, 1987, pp. 72 y 119). Por otra parte, el empleo del pronombre nosotros puede estar al servicio de una estrategia de cortesía negativa destinada a proteger la autonomía del interlocutor por medio del trato deferente, distanciado u honorífico; es lo que ocurre en el nosotros mayestático o de autoridad y en la pluralización del locutor como una figura digna de respeto o representante de un estatus social privilegiado. Si, en el caso del nosotros mayestático o de autoridad se amplifica el yo con una indicación de poder, en el nosotros corporativo o comercial el yo se expande al invocar cierto oficio, o bien alguna adscripción profesional o empresarial (como el vendedor que enuncia Nosotros garantizamos la atención personalizada a los clientes) (Brown y Levinson, 1987, p. 202).

En su estudio pragmático sobre la cortesía verbal, Henk Haverkate (1994) vinculó el empleo del pronombre personal nosotros al ejercicio de una forma de cortesía positiva que contribuye a la imagen positiva del interlocutor, esto es, a su aprobación y estima sociales. En los actos de habla exhortativos (como solicitudes o peticiones), el locutor puede servirse de una estrategia referencial indirecta seudoinclusiva, al pretender que la realización del acto requerido le corresponde a quien habla tanto como al interlocutor (pensemos en un profesor que dice a sus estudiantes Escribimos las respuestas en el cuaderno). Según Haverkate, se trataría de una forma del nosotros distinta de la inclusiva o la exclusiva, ya que se da cuando existe una relación asimétrica entre los interlocutores o alguna posición de poder del locutor; además, desde la perspectiva del hablante, introduce solidaridad simbólica con el interlocutor y disminuye la distancia social (Haverkate, 1994, pp. 29-30). Por otra parte, la primera persona del plural puede asociarse a una estrategia de desfocalización referencial en actos de habla como la aserción o la argumentación: el locutor se distancia de su papel como enunciador o lo minimiza, mediante un desplazamiento en las coordenadas del centro subjetivo de la deixis personal y la consiguiente manipulación del valor de verdad del enunciado. Según Haverkate, con la primera persona del plural se pueden llevar a cabo estrategias de desfocalización personal como la referencia seudoinclusiva, realizada en el plural de la modestia o el nosotros autorial; consiste en una estrategia persuasiva mediante la cual el locutor o autor elude la confrontación con su oyente o lector, a la vez que alude a un punto de vista compartido por los interlocutores (es el caso del autor que escribe: Concluiremos nuestro trabajo con la indicación de perspectivas futuras en el área). No obstante, el nosotros también puede llevar a cabo un tipo de desfocalización referencial en virtud del cual el locutor elude su responsabilidad por un acto con efectos desfavorables (como el médico que dice: Nos hemos equivocado de tratamiento). En la referencia seudoinclusiva, 
encontramos un formato de cortesía positiva que invita a fortalecer el contacto entre los interlocutores y la solidaridad grupal (Haverkate, 1994, pp. 118-121).

Además de los planteamientos semántico-discursivos centrados en la referencia deíctica y en la orientación en la situación verbal, o bien en la cortesía pragmática y en las estrategias de comunicación interpersonal, existen perspectivas críticas que han enfatizado la interpretación de los efectos ideológicos de la invocación del nosotros. Los pronombres personales resultan decisivos en el formato de análisis propuesto por la Lingüística Crítica de Fowler, Hodge, Kress y Trew, bajo los supuestos de que la comunicación lingüística se vincula con la estructura social y reproduce instrumentalmente las relaciones de poder, de modo que la ideología estaría discursivamente mediatizada. Según Fowler y Kress (1983), el empleo de los pronombres personales es uno de los aspectos relevantes -desde el punto de vista pragmático e interpersonal- en la expresión ideológica de las actitudes de locutores o escritores respecto a su audiencia y su temática; además, expresa ideológicamente las relaciones sociales o económicas con los interlocutores y el tipo de acción comunicativa realizada. En ese sentido, toda enunciación presupone un yo o un nosotros como fuente, aunque no siempre se manifieste en la estructura de superficie, o bien, se despersonalice. En el caso de la primera persona del plural, la fuente de la enunciación pretende hablar por el locutor y por algún otro: puede tratarse de otras personas, con exclusión del interlocutor (nosotros exclusivo) e, incluso, en nombre de alguna organización (nosotros corporativo); o bien podría tratarse de implicar discursivamente al interlocutor mediante un tenor solidario e íntimo, aunque no necesariamente sincero (nosotros inclusivo); asimismo, alguien con una posición de superioridad jerárquica en la interacción comunicativa podría invocar un nosotros amenazante que, sin embargo, incluya aparentemente al otro, un participante inferior (el nosotros seudoinclusivo mencionado por Haverkate) (Fowler y Kress, 1983, pp. 268-272).

En la ciencia del lenguaje actual, la herencia del tradicional abordaje semánticodiscursivo -que privilegia la dimensión deíctica y el valor referencial de los pronombres-, se pone de manifiesto a través de complejas tipologías de los tipos de referencia del nosotros dentro de distintos paradigmas lingüísticos. En su análisis de la gramática del nosotros, Johannes Helmbrecht (2002) insiste en que el pronombre de primera persona del plural es una expresión deíctica, en la medida en que hace referencia al enunciador actual como persona central de cualquier acto de habla. No obstante, junto a la referencia central al hablante, la primera persona no singular puede incorporar típicamente otros valores referenciales: en la primera persona dual, el hablante y el oyente o alguna otra persona; en la primera persona del plural, el hablante y un grupo de oyentes, o bien otro grupo de personas e, incluso, un grupo de oyentes y un grupo de terceras personas; en la primera persona dual inclusiva, solo el hablante y el oyente; en la primera persona dual exclusiva, solo el hablante y algún tercero; en la primera persona del plural inclusiva, tanto el hablante como un grupo de oyentes, o bien el hablante y un grupo de oyentes y algunos otros; por último, en la primera persona del plural exclusiva, el hablante y un grupo de terceros, pero no los oyentes (Helmbrecht, 2002, p. 34). En ese sentido los pronombres referentes al nosotros marcan, establecen y mantienen la pertenencia a algún grupo social, aunque no suele estar gramaticalizado -por motivos de economía linguiística-cuál sea la naturaleza del grupo de referencia (el nosotros nacional, el nosotros familiar, el nosotros de alguna asociación o club, etc.) como sí están marcados gramaticalmente el número o la inclusividad del nosotros. Según Helmbrecht, la relevancia identitaria y social del pronombre nosotros se aprecia sobre todo en sus usos no prototípicos, como los casos en que afirmamos 
Ganamos al relatar el triunfo del equipo que apoyamos, pero también el nosotros cortés empleado por el doctor que pregunta al paciente ¿Cómo estamos?, o bien el uso exhortativo del nosotros por parte del profesor que ordena a los alumnos Escribamos (2002, pp. 42-45).

Al abordar la construcción discursiva de la autorreferencia colectiva, Theodossia-Soula Pavlidou (2014) atribuye al pronombre nosotros una gama de valores referenciales que ponen de manifiesto la flexibilidad de esta expresión. Por una parte, cabe reconocer un grupo de valores referenciales de la primera persona del plural con un sentido indexical, que pueden cubrir distintos rangos de deixis personal en distintos paradigmas lingüísticos. En cierta forma de enunciación colectiva, nosotros se refiere al hablante y otros hablantes. En un nosotros dual e inclusivo, se hace referencia al hablante y oyente; mientras que, en un nosotros dual y exclusivo, la referencia se extiende al hablante y un tercero. En el plural inclusivo o en la referencia inclusiva a unos pocos (paucal), hay varias opciones de referencia: al hablante y algunos oyentes; al hablante, oyente y un tercero; al hablante, varios oyentes y uno o más terceros. En el caso del plural y el paucal exclusivo, nosotros se refiere al hablante y a más de un tercero. Por último, como expresión de un nosotros genérico, en cierto paucal y plural inclusivos, se hace referencia al hablante y a un grupo indefinido que puede abarcar la humanidad en su conjunto. Ahora bien, según Pavlidou, además de los valores referenciales típicos del nosotros, encontramos formas atípicas en que nosotros no hace referencia a un nosotros: en el caso del nosotros mayestático, el plural de la modestia, y el nosotros académico o de autoría, el referente es solo el hablante; en el nosotros directivo, exhortativo o seudoinclusivo (característico de relaciones asimétricas), se hace referencia al oyente únicamente; por último, en cierto nosotros integrativo, la referencia es una tercera parte o un grupo cualquiera de terceras personas (como al afirmar, en referencia a nuestro equipo, Ganamos la final) (Pavlidou, 2014, p. 4).

A pesar de la profusión de formas del nosotros en la literatura teórica, las investigaciones en Lingüística aplicada suelen limitar las posibilidades de la primera persona del plural a un repertorio más acotado. En algunos casos, se contempla el nosotros inclusivo, el exclusivo, el invertido (que solo hace referencia a los oyentes) o el totalmente exclusivo (que coincide con un significado genérico, sin hacer referencia a ninguno de los interlocutores) (Bazzanella, 2002). En otros casos, se considera el nosotros inclusivo (ya sea el integrativo, que comprende a ambos interlocutores, o bien el expresivo, con un énfasis adicional en la solidaridad), el exclusivo (el nosotros editorial o de la modestia, el uso coercitivo o el plural mayestático) y el nosotros invertido (Bull y Fetzer, 2006). A veces, se distinguen el nosotros inclusivo, un nosotros omnicomprensivo, el nosotros excluyente del interlocutor y un nosotros errante, ambivalente y fluido, cuya referencia varía a través del discurso, de manera que se juega caleidoscópicamente con distintas identificaciones colectivas (Petersoo, 2007).

Del mismo modo que se han reconocido distintos valores referenciales para el pronombre nosotros, también se le han atribuido diferentes funciones comunicativas, que eventualmente podrían coincidir en una sola expresión: en la función directiva, nosotros se refiere al oyente, en un contexto en que se quiere que este realice algo que le interesa al hablante (como quien pide silencio al decir ¿Podemos callarnos?); en la función integrativa, el hablante indica un vínculo social con un grupo (como el forofo que afirma Tenemos la liga ganada); en la función fática, solo se dan indicaciones comunicativas (como quien dice en la conversación ¿Qué estábamos diciendo?); en la función expresiva, el hablante se inviste con la autoridad grupal para expresar autoridad o representatividad (como el vendedor que dice No tememos a la competencia); en la función cognitiva, nosotros se emplea para introducir información nueva 
(por ejemplo, Nosotros tenemos menos genes que otras especies); incluso podría reconocerse una función exculpatoria, en la cual quien dice nosotros evita la responsabilidad (como ocurre cuando el responsable dice a la audiencia Prometemos no hacerlo nuevamente) (Borthen y Thomassen, 2014, pp. 75-76). En todo caso, resulta posible relacionar el dominio referencial y las funciones discursivas del nosotros: en el plural mayestático, se hace referencia al hablante; en el nosotros inclusivo, ya sea integrativo o representativo, la referencia consiste en un grupo de gente que incluye al hablante y al oyente; en el nosotros exclusivo y en el plural de la modestia académico, se hace referencia a un grupo de personas que incluye al hablante, pero excluye al oyente; en el nosotros coercitivo, la referencia comprende a un grupo de gente que incluye al oyente, pero no al hablante (Fetzer, 2014, p. 337).

\section{Nosotros en español}

Con respecto al pronombre de primera persona del plural en español, la tradición gramatical ha tratado de establecer sus características formales, funcionales y semánticas ${ }^{1}$. En los estudios gramaticales de Rodolfo Lenz (1925) encontramos un notable planteamiento de los rasgos formales y significados del nosotros en español. En ese sentido, Lenz ya asoció el pronombre personal de primera persona a la autorreferencia sustantiva de quien se concibe en sí y para sí como centro de la enunciación, al decir yo y dirigirse conversacionalmente a un tú en el diálogo (1925, pp. 225-226). Por otra parte, así como la primera persona designa a quien habla y la segunda al destinatario de la enunciación, la tercera persona remitiría a cualquier tipo de entidad o contenido de la comunicación (Lenz, 1925, p. 238). La gramática de Lenz sostenía que en español no hay una forma dual que refiera conjuntamente a las dos personas involucradas en el acto de la palabra y, en estricto rigor, tampoco existiría un genuino plural del yo, ya que nosotros no designa a cierto número de una misma entidad (el yo multiplicado), sino a una conjunción del yo y de otros, con exclusión del interlocutor. Según Lenz, el castellano antiguo presentaba una diferencia entre el nosotros exclusivo y una forma nos inclusiva; pero posteriormente se confundieron la forma del plural inclusivo y la del exclusivo en el español moderno (1925, pp. 227-229). Lenz también describe aquellos empleos del nosotros en que tiene lugar una sustitución ceremonial del pronombre personal, ya se trate del reemplazo del singular por un plural de la modestia (el cual incluye a la audiencia para no parecer impositivo), o bien la designación en plural de alguna autoridad (que parece hablar en nombre de quienes gobiernan con él), como ocurre en el nosotros mayestático (Lenz, 1925, pp. 239-240).

Las gramáticas del español han reiterado frecuentemente los planteamientos de Lenz, al sostener que los pronombres personales se refieren al papel de los participantes en el discurso; también han reproducido la tesis de que no se puede interpretar el plural de la primera persona del mismo modo que los plurales de la segunda o tercera persona, ya que vosotros designa a varios tú, y ellos a un varios él, pero nosotros no designa a un conjunto de yoes, sino a yo y otros (Real Academia Española, 1973, p. 203; Alarcos, 2000, pp. 70-73)². Al asumir que el plural

1 Uno de los evaluadores anónimos me recordó la importancia del trabajo de José Rufino Cuervo (1998) para remarcar el valor de refuerzo asociado a la aparición explícita del pronombre nosotros.

2 Agradezco a uno de los evaluadores anónimos la indicación de otras fuentes relevantes para realizar la comparación entre los pronombres nosotros y vosotros; concretamente, los artículos de Gili Gaya (1946), Spitzer (1947) y Nowikow (1994). 
de la primera persona no designa a un conjunto de emisores simultáneos (a una enunciación colectiva solo excepcionalmente realizada en nuestra cultura), sino a la presencia de un sujeto de la enunciación y a la copresencia de varios individuos que no necesariamente son locutores, se ha podido argumentar que el nosotros no es realmente un plural numérico y no es un enunciador homogéneo; solo se referiría implícitamente a quien habla (un yo camuflado), pero puede simbolizar la pluralidad al invocar con el nosotros cierta representatividad, investidura mayestática o evitación de la responsabilidad (Rivarola, 1984). En todo caso, también se ha defendido que nosotros es efectivamente el plural del yo, bajo el argumento de que quienes niegan esa posibilidad no distinguen significado y referencia ni respetan la irreductibilidad de las tres personas gramaticales. En conclusión, nosotros sería el plural de yo de modo distinto a otras categorías: mientras yo significa un hablante indiviso, nosotros solo significaría un hablante plural y dividido, aunque no tenga como referencia un conjunto numérico o adición cuantitativa de yoes singulares (Almela, 2000).

En ese sentido, las actuales gramáticas del español asumen que la primera persona puede realizar un plural ficticio y exhibir una referencia singular, como ocurre en las formas del plural de la modestia y el plural mayestático; o bien puede referir a otros con los que el emisor se identifica (el nosotros representativo de quien exclama ;Ganamos!) e, incluso, puede darse una alteración de la referencia para empatizar con el interlocutor (como ocurre en el plural asociativo utilizado por el doctor que pregunta ¿Cómo estamos hoy?) (Fernández Soriano, 1999, p. 1218). Hasta la más reciente gramática de la Real Academia Española del 2009 asocia los pronombres personales a la designación deíctica de los participantes en el discurso (2010, pp. 299-304). Además, considera que en la primera persona del plural no tiene por qué haber coincidencia entre el número gramatical y la referencia (como ocurre en el nosotros mayestático, o bien en el plural de la modestia o de autor, que designan a un solo hablante). Por otra parte, afirma que la forma nosotros puede tener una referencia imprecisa y designar a cualquiera (como es el caso del nosotros genérico), o bien designar cortés o empáticamente al interlocutor (como pasa en el nosotros asociativo) (Real Academia Española, 2010, p. 304).

En distintos estudios sobre la deixis pronominal y sobre la referencia a los participantes en el discurso, se han descrito diferentes usos del nosotros en español, con funciones comunicativas matizadas y con modos diversos de acotar el espacio comunicativo y el protagonismo de los interlocutores. Ya en el lenguaje coloquial podemos reconocer una serie de empleos de la primera persona del plural que cuestionan la referencia deíctica y parecen introducir algún tipo de desplazamiento del centro deíctico de referencia o alguna forma de expresión subjetiva o intersubjetiva (Vigara, 2000; De Cock, 2009, 2011):

1. En ese orden de ideas, hay una serie de empleos apelativos en que nosotros se refiere básicamente a nuestro interlocutor. Es el caso del saludo convencional: “Cómo estamos?”. También se da esta forma del nosotros en la orden implícita de una profesora a sus alumnos: "Podemos callarnos de una puñetera vez" (citados en Vigara, 2000, p. 103).

2. Hay expresión de subjetividad en los empleos coloquiales de la primera persona del plural que permiten eludir la responsabilidad o distribuir el mérito: "Ay, y el mando no lo hemos traído”; “Hemos traído empanada!” (citados en De Cock, 2009, p. 255).

3. Como expresión intersubjetiva que incluye a ambos interlocutores, existe un uso exhortativo de la primera persona del plural en la forma coloquial vamos, ya sea empleada como interjección, o bien como auxiliar de una perífrasis verbal. En ambos empleos, parece tratarse 
de una atenuación, al incluir al enunciador: "Vamos, yo lo veo muy generalizado"; "Bueno, pues, venga, vamos a comer" (citados en De Cock, 2009, p. 259).

En el discurso periodístico y en los medios de comunicación de masas, se han identificado algunas formas recurrentes de la primera persona del plural que se caracterizan por su indeterminación y opacidad referencial, pero también por su sentido intersubjetivo (Aijón, 2013; Aijón y Serrano, 2013; Serrano y Aijón, 2013):

1. Existe un uso de nosotros que excluye al interlocutor, como ocurre típicamente cuando se quiere enfatizar la representatividad del hablante; por ejemplo: "nosotros somos una empresa en expansión / vamos a contratar varias aeronaves y necesitamos contratar gente / en estos momentos nadie va a ser eventual" (citado en Serrano y Aijón, 2013, p. 420).

2. Eventualmente, se da una exclusión empática del interlocutor, de manera que el locutor intenta alinearse con el oyente, como es el caso en la siguiente formulación en una emisora: "estas son algunas / de las noticias locales de esta jornada / pero tenemos otras / que les avanzamos a continuación” (citado en Serrano y Aijón, 2013, p. 421).

3. En los empleos inclusivos del nosotros en los medios, cabe reconocer distintos rangos de inclusión a la hora de incorporar al oyente o la audiencia en la información. En el siguiente ejemplo, la inclusión del interlocutor en el nosotros mediático propicia un efecto de identificación: "hemos pasado los últimos cuatro años bajo la crispación, la opresión y hasta con el sentimiento de culpabilidad que te da el sentirte perseguido por decir lo que piensas" (citado en Serrano y Aijón, 2013, p. 428).

En el caso de la deixis personal en el discurso político, se han reconocido numerosas formas del nosotros, dependiendo del enmarcado del espacio comunicativo y de la referencia a los interlocutores (Blas Arroyo, 2000; De Cock, 2009; Gelabert-Desnoyer, 2006):

1. La primera persona del plural puede emplearse para desdibujar la responsabilidad de los participantes mediante una referencia ambigua e indeterminada a toda la población, como ocurre en la siguiente intervención de Felipe González: "porque tendremos épocas de crisis y épocas de prosperidad y nosotros estamos amortiguando la crisis con un sistema de protección social... eso es salario indirecto Sr. Aznar" (citado en Blas Arroyo, 2000, pp. 4-5).

2. También existe un uso partisano o beligerante del nosotros, una modalidad de nosotros exclusivo y en abierta contraposición al interlocutor o a su grupo; es lo que ocurre en la siguiente intervención de Aznar: "los que creemos en la división de poderes, los que creemos en la separación del ejecutivo... queremos restablecer ese equilibrio señor González" (citado en Blas Arroyo, 2000, p. 5).

3. Ocasionalmente, el nosotros del discurso político puede no solo hacer referencia a los integrantes del propio partido, sino invocar a toda la población (o a terceros no involucrados en el debate) contra el interlocutor, como ocurre en la siguiente intervención de Aznar: "yo creo que los españoles ya sabemos... que nuestro país vive una crisis muy profunda, extraordinariamente profunda, los españoles sabemos también en este momento que tenemos tres millones trescientos mil parados..." (citado en Blas Arroyo, 2000, p. 9).

4. No obstante, existe una forma de nosotros inclusivo que comprende el espacio discursivo intermedio de ambos interlocutores, a pesar de la relación polémica entre partidos; así se 
aprecia en la siguiente intervención de Felipe González: "si usted tuviera en sus expresiones... la mitad del grado de respeto que yo tengo con usted estaríamos en una posición de un poco más de equilibrio" (citado en Blas Arroyo, 2000, p. 13). O bien puede darse un nosotros inclusivo aumentado, que remita a ambos participantes y a la audiencia; aparece en la siguiente intervención de Felipe González:

\footnotetext{
estamos celebrando aquí un debate y otro debate que me parece muy bien además y que ya he expresado que estoy contento de que se celebre y hemos celebrado otro en Antena 3 señor Aznar durante dos semanas seguidas y los dos profesionales que están moderando este debate son profesionales que vienen de Televisión española (citado en Blas Arroyo, 2000, p. 13).
}

5. Eventualmente, el uso inclusivo de nosotros en el discurso político puede vincularse a alguna forma de contraste o discriminación grupal respecto a otros colectivos o naciones, como si se realizara una oposición entre nosotros (los interlocutores) y ellos: "Ya pero eso lo hacemos nosotros con los marroquíes y con todo el que nos dé la gana" (citado en De Cock, 2014, p. 132).

6. Además de las formas del nosotros inclusivo y del representativo (que hace referencia al hablante y al grupo político propio o a la población general), en el discurso político se hace presente un nosotros experiencial, el cual comprende tanto al hablante como al género humano en su conjunto. Encontramos este nosotros genérico en la siguiente intervención de la diputada Castro:

25 años después de haber conseguido iniciar el camino de la democracia seguimos sin entender que los seres
humanos somos sexuados desde que nacemos hasta que nos morimos. Hay varios colectivos sociales a los que
sistemáticamente se les niega el derecho a la sexualidad, pero voy a significar dos por su importancia: uno es el
colectivo de los jóvenes y otro el de los mayores. Es una pura falacia. Vuelvo a repetir: los seres humanos nacemos
sexuados y morimos siendo seres humanos sexuados (citado en Gelabert-Desnoyer, 2006, p. 10).

7. En el discurso político podemos encontrar un nosotros vocativo que no se refiere al hablante, sino al interlocutor; de ese modo, se puede cuestionar al interlocutor sin afectar su imagen. Así ocurre en la siguiente declaración del ministro de Justicia Michavila:

podemos confundir, como ha hecho S.S. hoy aquí, la ballena de Jonás con la de Job, como decía usted. Incluso ha hablado usted del carro de fuego de Jonás, y yo creo que era de Elías. Podemos confundir esas citas y también confundir a la presidenta de la Cámara con la ministra. Considero que en un parlamento esas confusiones son lógicas. Pero lo que no podemos confundir es la realidad social de la que está hablando, porque cuando se tergiversa esa realidad social, señoría, se sacan consecuencias distintas (citado en Gelabert-Desnoyer, 2006, p. 11).

8. Aunque no haga referencia específica a alguno de los interlocutores, encontramos un empleo gramaticalizado de la primera persona del plural como marcador discursivo, en expresiones del tipo vamos y digamos. Es el caso de la siguiente intervención del diputado Silva:

Estamos hablando -datos del año 2001- de 7.590 empresas, que dan trabajo aproximadamente a 280.000 trabajadores, que exportan por unos 14.800 millones de euros y cuya cifra de exportaciones en el año 2001 se aproxima al billón de pesetas, concretamente 5.991 millones de euros (citado en Gelabert-Desnoyer, 2006, p. 12).

Por último, en el discurso académico se han identificado distintos empleos de la primera persona del plural que se sitúan entre la personalización y la despersonalización de la voz del autor (García Negroni, 2008; Manuel Oloume, 2015):

1. En el nosotros de la modestia o nosotros autoral, el escritor atenúa la responsabilidad por su labor, o bien se encuentra en una posición académica inferior y no quiere responsabilizarse solo; por ejemplo: "En este sentido nos proponemos establecer las bases que permitan conocer 
primero la hacienda local de Córdoba en la segunda mitad del siglo XVI” (citado en García Negroni, 2008, p. 14).

2. La primera persona del plural puede emplearse con una referencia genérica, como un nosotros colectivo, de manera que el autor se incluye en el conjunto de la comunidad científica o de la sociedad:

La sociedad en la que vivimos, con su entretejido social, económico, político y cultural, es el sustrato del imaginario que impregna nuestro decir, y aflora de manera particularmente patente cuando la voz que integramos en nuestro discurrir se hace eco de construcciones discursivas colectivas (citado en García Negroni, 2008, p. 13).

3. Mediante el uso del nosotros inclusivo, se refuerza el vínculo entre el lector y el autor, que es quien dirige la lectura: "Como veremos, estos elementos que Halperín descarta encuentran explicación en el ideario rebelde" (citado en García Negroni, 2008, p. 14).

4. Existe un empleo exhortativo de la primera persona del plural en el discurso académico, que transmite instrucciones, órdenes o consejos, sin cuestionar la imagen del interpelado: "Volvamos de nuevo a nuestro ejemplo" (citado en Manuel Oloume, 2015, p. 80).

5. Cabe distinguir otro empleo del nosotros en el discurso académico que evoca la implicación del destinatario, como si se tratase de un nosotros simultáneamente inclusivo y exhortativo, una invitación a compartir el punto de vista del autor y una prescripción de ciertas acciones: "Pero rescatemos brevemente la trama argumental de este caso" (citado en Manuel Oloume, 2015, p. 81).

En cuanto a las funciones que puede asumir el nosotros, en el discurso político se puede distinguir un empleo ligado al registro profesional del grupo político del que se es parte, un nosotros confrontacional, un empleo al servicio de la gestión del diálogo o del énfasis temático y, asimismo, un nosotros que permite la expresión de autoalabanza (Gelabert-Desnoyer, 2006). Como se puede apreciar, tanto en el caso del discurso político como en el discurso coloquial y mediático, las funciones de la primera persona del plural no se limitan a la deixis personal, a la identificación de los participantes o a la acotación del contexto discursivo; y es que el empleo del nosotros cumple importantes funciones relacionadas con la expresión subjetiva, la vinculación intersubjetiva y la manifestación de actitudes hacia los interlocutores, así como con la conceptualización genérica y la expresión de modalidades deónticas (obligación, prohibición o permisión), e, incluso, existen funciones relacionadas con la estructuración de la interacción comunicativa y del discurso, al contribuir a la construcción de turnos (De Cock, 2014, p. 267).

\section{Una sistematización de los usos del nosotros y de la primera persona del plural ${ }^{3}$}

Cualquier intento de sistematizar los usos del nosotros y la gramática de la primera persona del plural ha de tomar en consideración ciertas premisas que se desprenden del estado de la cuestión en torno a la deixis personal y la subjetivación en el discurso:

3 Como ocurre en gran parte de los trabajos incluidos en esta revisión, no se hace la distinción entre los usos expresos del pronombre nosotros y la gramática de la primera persona del plural. 
1. Existen modalidades de deixis en las cuales la orientación en el espacio comunicativo presupone no solo un origen de las coordenadas mostrativas centrado en la primera persona, sino también algún otro punto de referencia y, eventualmente, una coordinación duocéntrica (como ocurre al emplear los demostrativos este, ese o aquel, dependiendo de la posición de los dos interlocutores); además, el origen de la deixis puede desplazarse (Escavy, 2011, pp. 76-88). En el caso de la deixis personal asociada al nosotros, el origen de la enunciación puede desplazarse y situarse en distintas áreas del espacio discursivo que comprende al locutor, al oyente y a terceros (incluso puede darse un empleo de nosotros no centrado referencialmente en el yo, sino en el tú, como ocurre en los empleos exhortativos o corteses de la primera persona del plural). Además, en algunos usos del nosotros resulta muy relevante el valor de contraste o las marcas de inclusividad que permiten diferenciar, respecto de otros, al grupo del cual es parte el locutor, ya se trate de los interlocutores o de terceros (como ocurre en el nosotros exclusivo). En el caso del discurso político, los usos del nosotros se asocian al despliegue de cierto guion discursivo y configuran el enmarcado del espacio comunicativo, así como la asignación de papeles culturales y políticos a los participantes (Zupnik, 1994).

2. Como la Lingüística Cognitiva ha argumentado, el enmarcado o conceptualización del trasfondo comunicativo no solo se lleva a cabo mediante las referencias deícticas que enfocan objetivamente la situación de interacción comunicativa, pues también resulta preciso considerar las diferentes construcciones subjetivas del trasfondo enunciativo y los distintos modos en que se perfila a los participantes en la escena discursiva (Brisard, 2002). En ese sentido, el empleo del nosotros no tiene por qué hacer referencia objetiva a algún colectivo inclusivo (de hecho, es tal la ambivalencia y opacidad referencial que nosotros puede designar a toda una variedad de grupos); además, la primera persona del plural permite expresar una orientación empática hacia la coincidencia de puntos de vista, pero también la despersonalización de la referencia personal individualizada, para distribuir las responsabilidades, las ventajas o los perjuicios (Serrano y Aijón, 2013).

3. Junto con las funciones relacionadas con la identificación referencial y la orientación discursiva, la primera persona del plural puede desempeñar una importante función interactiva, al facultar la cooperación comunicativa y la negociación del significado y del espacio discursivo, así como la eventual imposición de un marco consensual o comprensión compartida (por ejemplo, en los usos del nosotros por cortesía o en los usos exhortativos) (Scheibman, 2002, pp. 101-103). De ese modo, la deixis personal realizada con el nosotros tiene importantes rendimientos para la expresión subjetiva, para la vinculación intersubjetiva y para la modulación de las actitudes y creencias hacia los interlocutores (De Cock, 2014, pp. 267-269).

En nuestra propuesta de sistematización de la gramática del nosotros y de la primera persona del plural, los valores referenciales no se asignan solo en virtud de la presencia o ausencia del locutor, el oyente o algún tercero (como ocurre en muchos análisis de la referencia de la primera persona del plural). Además de la marca de presencia $(+)$ para indicar referencia directa a alguno de los participantes en la situación comunicativa, nuestra propuesta considera una marca de alusión, de presencia disminuida o de referencia indirecta $( \pm)$, para dar cuenta de aquellas formas de nosotros que implican cierta forma de exclusión relativa o atenuación del locutor, del interlocutor o de terceros; en esta representación, la ausencia de valor referencial no implicará marca alguna. La referencia directa o atenuada al locutor en el nosotros podría estar vinculada con la forma léxico-gramatical de realización de la primera persona del plural (como marca de persona o como sujeto pronominal). Por su parte, el modo de realización léxico-gramatical de la primera 
persona del plural y la eventual aparición del pronombre nosotros se asocian tanto a fenómenos de prominencia cognitiva (la focalización de la atención y la accesibilidad del referente) como a la economía de la informatividad textual y la expresión subjetiva o la intención interactiva (Serrano, 2013). Puesto que compartimos la idea de que nosotros no constituye un plural de yoes, sino una división o distribución de la enunciación, se asumirá que los lugares del yo, el tú y la tercera persona pueden ser ocupados por uno o varios individuos. Siguiendo estas convenciones, cabe distinguir 10 formas de nosotros o primera persona del plural en castellano, con distintos valores referenciales, que aparecen representadas en la Tabla 1:

Tabla 1. Valores referenciales de distintas formas del nosotros

\begin{tabular}{llll}
\hline nosotros & yo & tú & tercera persona \\
\hline de la modestia & \pm & & \pm \\
de cortesía & \pm & + & + \\
retórico & \pm & \pm & \\
exculpatorio & \pm & \pm & \pm \\
mayestático & + & & \\
asociativo & + & + & + \\
genérico & + & + & + \\
partisano & + & \pm & \pm \\
discriminatorio & + & + & + \\
representativo & + & & \\
\hline
\end{tabular}

Fuente: Elaboración propia.

Según se puede apreciar en la Tabla 1, el valor referencial de alusión o referencia indirecta $( \pm$ ) puede asociarse a la primera persona, como ocurre en todos aquellos casos en que existe alguna forma de atenuación del papel discursivo del enunciador. En otros casos, el emisor aparece marcado con un valor referencial positivo (+), para representar cierta amplificación o potenciación del papel discursivo del enunciador. Si consideramos ese reparto funcional de papeles en la enunciación y añadimos a los coprotagonistas o antagonistas presentes en el espacio discursivo del nosotros, se podría obtener la siguiente matriz de opciones sistemáticas de significación para la primera persona del plural:

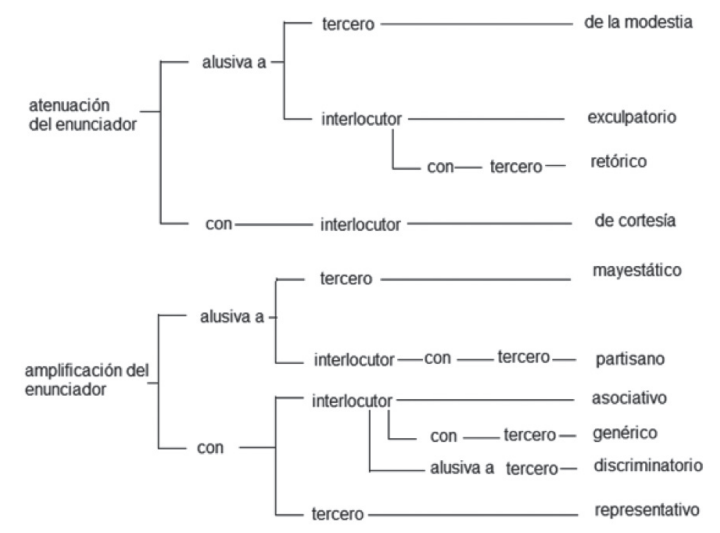

Figura 1. Sistema de opciones de significación del nosotros

Fuente: Elaboración propia. 
Cada una de las formas de realización del nosotros o de la primera persona del plural no solo involucra valores referenciales directos o indirectos, así como funciones discursivas de atenuación o amplificación del enunciador mediante la conjunción con otros o la alusión a interlocutores o terceros. Además, cada forma de la primera persona del plural se asocia a cierta delimitación del espacio discursivo y a distintos formatos de conceptualización de la situación comunicativa, ya sea mediante la focalización de algunos participantes o su indicación tangencial. A continuación, brindaremos un ejemplo de cada una de las realizaciones del nosotros y propondremos una representación esquemática de la conceptualización del espacio discursivo involucrada. Con los tres círculos pequeños, se representan los lugares del hablante $(\mathrm{H})$, del oyente $(\mathrm{O})$ y de terceros $(\mathrm{T})$; el área circular cubre el espacio discursivo conceptualizado en cada empleo del nosotros e indica la focalización o indicación alusiva de los participantes en la situación comunicativa:

1. El plural de la modestia corresponde a cierta desfocalización o despersonalización del lugar del enunciador, mediante el posicionamiento como un cualquiera que habla y, por tanto, a través de la alusión a terceros. Se hace presente con frecuencia en el discurso académico, como ya vimos en el siguiente ejemplo: "En este sentido nos proponemos establecer las bases que permitan conocer primero la hacienda local de Córdoba en la segunda mitad del siglo XVI" (citado en García Negroni, 2008, p. 14). La conceptualización del espacio discursivo realizada en este nosotros aparece representada en la Figura 2; como puede apreciarse, el área del espacio discursivo cubre un ámbito despersonalizado, que solo tangencialmente alude al hablante y al punto de vista de terceros:

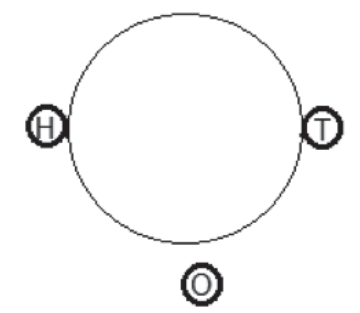

Figura 2. Conceptualización del espacio discursivo en el nosotros de la modestia Fuente: Elaboración propia.

2. El nosotros exculpatorio lleva a cabo una desfocalización del papel del enunciador con el propósito de desresponsabilizarlo, a la vez que alude proyectivamente al oyente en este ejercicio de desplazamiento de la culpa. Por citar un ejemplo, es lo que ocurre cuando el médico le dice a su paciente: "Nos hemos equivocado de tratamiento" (citado en De Cock, 2011, p. 2766). Representamos la conceptualización del espacio discursivo en la Figura 3, que comprende un área despersonalizada solo alusivamente indicativa del emisor y el interlocutor:
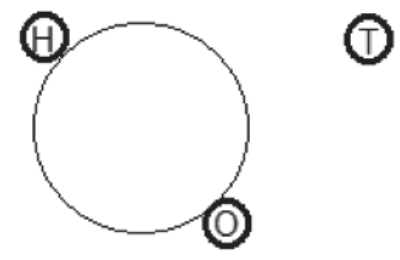

Figura 3. Conceptualización del espacio discursivo en el nosotros exculpatorio Fuente: Elaboración propia. 
3. El nosotros retórico es una realización de la primera persona del plural que aparece frecuentemente en el discurso académico y, particularmente, en los formatos pedagógicos de la comunicación académica. Consiste en cierto desplazamiento del papel del enunciador y en una focalización de la comunicación en la posición discursiva de un tercero, que podría ser cualquiera (ese no-lugar de la perspectiva científica), a la vez que hay una clara alusión persuasiva al receptor o al lector. Ni el emisor ni el receptor están referencialmente enfocados en este nosotros retórico, aunque ambos aparecen tangencialmente en el espacio discursivo como un enunciador autorizado por terceros y un receptor interpelado por el discurso del saber. Veamos un ejemplo del discurso académico, ya mencionado: "Pero rescatemos brevemente la trama argumental de este caso" (citado en Manuel Oloume, 2015, p. 81). En el discurso mediático, este nosotros retórico se asocia a cierta seudoinclusión empática de la audiencia; es lo que ocurre en el siguiente ejemplo, que podría atribuirse a un lector de noticias de un canal (probablemente, de las notas de alguna agencia noticiosa externa): "estas son algunas / de las noticias locales de esta jornada / pero tenemos otras / que les avanzamos a continuación" (citado en Serrano y Aijón, 2013, p. 421). Según se aprecia en la Figura 4, este nosotros o primera persona del plural cubre un área discursiva tan indeterminada como las terceras personas en quienes pone el foco:

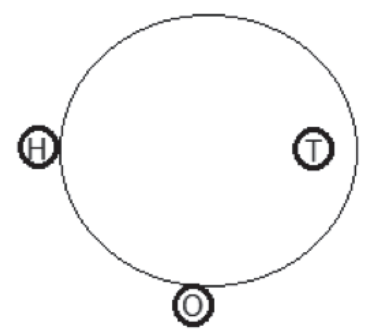

Figura 4. Conceptualización del espacio discursivo en el nosotros retórico

Fuente: Elaboración propia.

4. El nosotros de cortesía lleva a cabo una desfocalización del papel del enunciador, para poner en el foco referencial al oyente. De ese modo, se contribuye pragmáticamente a la protección de la imagen pública del oyente, mediante cierta asunción (a veces, empática) de la perspectiva del interlocutor, particularmente cuando hay alguna exhortación. Por repetir un par de ejemplos: “Cómo estamos?”, "Podemos callarnos de una puñetera vez” (citados en Vigara, 2000, p. 103). El área discursiva cubierta por este nosotros o primera persona del plural cortés se representa en la Figura 5:

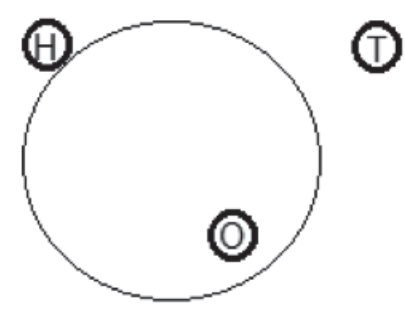

Figura 5. Conceptualización del espacio discursivo en el nosotros de cortesía Fuente: Elaboración propia. 
5. El plural mayestático realiza una ampliación focal del papel del emisor, por medio de una alusión a terceros que lo autorizan en su cargo o investidura. Es lo que ocurre en el siguiente ejemplo, tomado de un discurso del papa Juan XXIII en 1961:

La circunstancia que motiva esta grata audiencia de hoy es ya, por sí misma, como lo adivináis, muy emotiva para Nos. Nuestro octogésimo aniversario, y al mismo tiempo el tercero de nuestro pontificado: ¡qué invitación para hacer subir al Todopoderoso nuestras acciones de gracias! (Juan XXIII, 1961, párr. 2).

Representamos el área discursiva de este nosotros mayestático en la Figura 6.

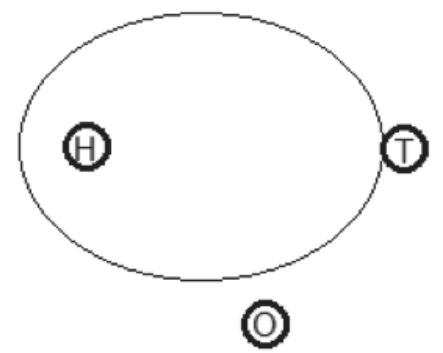

Figura 6. Conceptualización del espacio discursivo en el plural mayestático Fuente: Elaboración propia.

6. El nosotros partisano es un empleo de la primera persona del plural muy característico del discurso político, en la medida en que posibilita enfocar al enunciador y amplificar su posición con algún grupo de referencia, para marcar cierta oposición alusiva frente a un interlocutor excluido. Lo reconocemos en la siguiente interpelación de Aznar: "los que creemos en la división de poderes, los que creemos en la separación del ejecutivo... queremos restablecer ese equilibrio señor González" (citado en Blas Arroyo, 2000, p. 5). La delimitación polémica del espacio discursivo se representa en la Figura 7.

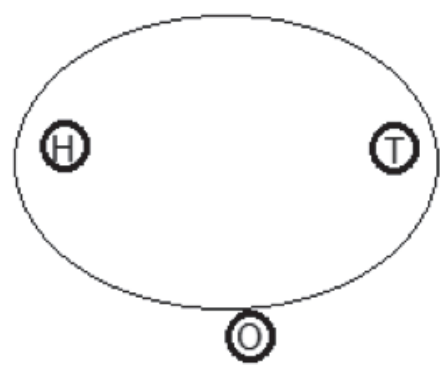

Figura 7. Conceptualización del espacio discursivo en el nosotros partisano Fuente: Elaboración propia.

7. El nosotros asociativo corresponde a un plural de primera persona inclusivo, cuyo foco referencial se pone en ambos interlocutores, para resaltar la vinculación interpersonal y la coordinación empática de perspectivas. Podemos reconocer este empleo del nosotros o de la primera persona del plural en algunos ejemplos ya mencionados: "Bueno, pues, venga, vamos a comer" (citado en De Cock, 2009, p. 259); "si usted tuviera en sus expresiones... la mitad del grado de respecto que yo tengo con usted estaríamos en una posición de un poco más de equilibrio" (citado en Blas Arroyo, 2000, p. 13). Representamos el área discursiva cubierta por este nosotros inclusivo en la Figura 8. 


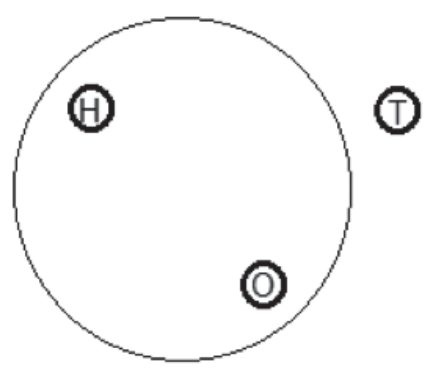

Figura 8. Conceptualización del espacio discursivo en el nosotros asociativo Fuente: Elaboración propia.

8. El nosotros genérico constituye la versión más amplificada de un nosotros inclusivo; comprende en su foco referencial al enunciador, al oyente y a cualquier persona, de manera que adquiere un alcance discursivo tan universal como impersonal. Podemos identificarlo en el siguiente ejemplo: "los seres humanos nacemos sexuados y morimos siendo seres humanos sexuados" (citado en Gelabert-Desnoyer, 2006, p. 10). En la Figura 9 se representa la cobertura referencial comprehensiva e indeterminada de este tipo de nosotros o primera persona del plural.

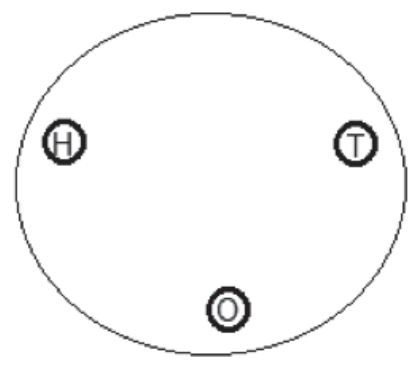

Figura 9. Conceptualización del espacio discursivo en el nosotros genérico Fuente: Elaboración propia.

9. El nosotros discriminatorio resulta frecuente en el discurso político, aunque también se manifiesta en la expresión de prejuicios cotidianos en el discurso coloquial. Se trata de una forma de plural de primera persona que focaliza la participación del enunciador y sus interlocutores en un mismo grupo, para marcar la diferencia frente al ellos de algún otro colectivo, indirectamente aludido en la autopresentación del nosotros. Lo reconocemos en el siguiente ejemplo: "Ya, pero eso lo hacemos nosotros con los marroquíes y con todo el que nos dé la gana" (citado en De Cock, 2014, p. 132). La representación del espacio discursivo se encuentra en la Figura 10.

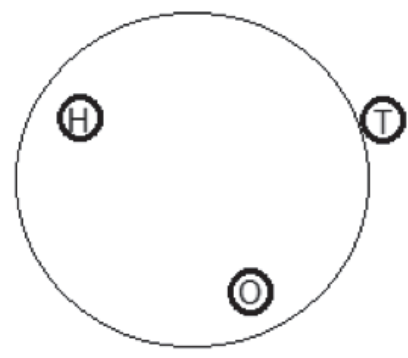

Figura 10. Conceptualización del espacio discursivo en el nosotros discriminatorio Fuente: Elaboración propia. 
10. El nosotros representativo introduce una focalización ampliada del nosotros o de la primera persona del plural como parte de un referente colectivo más amplio (los integrantes de nuestra empresa, los miembros de nuestro partido, los colegas de cierta disciplina académica, etc.), de manera que provee una autorización suplementaria al hablante. Está presente en el siguiente ejemplo: "nosotros somos una empresa en expansión / vamos a contratar varias aeronaves y necesitamos contratar gente / en estos momentos nadie va a ser eventual" (citado en Serrano y Aijón, 2013, p. 420). En la representación de la Figura 11 se puede distinguir el ámbito referencial de este nosotros, que deja fuera al interlocutor.

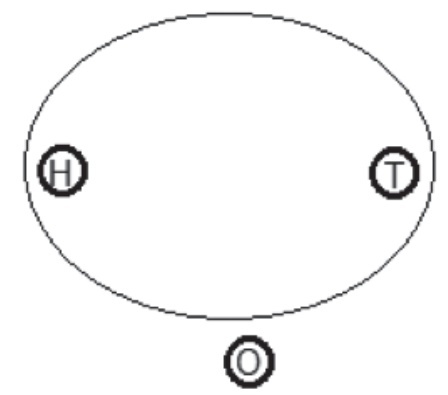

Figura 11. Conceptualización del espacio discursivo en el nosotros representativo Fuente: Elaboración propia.

\section{Conclusión}

Para concluir, quisiéramos clarificar que esta propuesta de sistematización de los valores referenciales, las opciones funcionales de significación y los modos de conceptualización del espacio discursivo asociados a la primera persona del plural no constituye un orden definitivo y cerrado; no pretende agotar la fluidez y opacidad referencial del nosotros ni tampoco los diversos problemas vinculados a la presencia o no de un sujeto pronominal, a los diferentes casos pronominales o a los usos matizados del nosotros en distintos géneros discursivos. No obstante, cuenta con la ventaja de que, para los ejemplos seleccionados a partir del estado de la cuestión, establece una relación interna entre los valores referenciales, las opciones funcionales y los enmarcados conceptuales, y aporta una modelización plausible y parsimoniosa del comportamiento semántico-discursivo del pronombre de primera persona del plural.

Sin duda, el sofisticado repertorio de empleos del nosotros que hemos sistematizado constituye una llamada de atención y una señal de reserva frente a aquellos acercamientos filosóficos, sociológicos o psicológicos que sobreestiman la capacidad del pronombre de primera persona del plural para forjar identidades colectivas frente a alguna clase de ellos. Como contrapartida, nuestro análisis de la gramática del nosotros y de la primera persona del plural pone de manifiesto los múltiples y sofisticados modos de realización discursiva de la interacción comunicativa, de los lazos sociales y de las formas de inclusión y exclusión colectivas.

Por nuestra parte, nos basta si hemos conseguido ordenar la dispersión de usos del nosotros en las ciencias del lenguaje (con la limitación evidente de que no se consideró la distinción entre el uso expreso del pronombre y la forma gramatical de la primera persona del plural); a otros les corresponderá investigar el haz de problemas gramaticales ligados a la primera persona del plural en presencia o ausencia del sujeto pronominal, en diferentes 
posiciones oracionales del pronombre, en los distintos casos y con tiempos verbales diferentes, así como en diversos géneros de discurso.

\section{Bibliografía}

Aijón Oliva, M. A. (2013). On the meanings and functions of grammatical choice: the spanish first-person plural in written-press discourse. Pragmatics, 23(4), 573-603.

Aijón Oliva, M. A. y Serrano, M. J. (2013). Style in syntax: Investigating variation in Spanish pronoun subjects. Bern, Switzerland: Peter Lang, International Academic Publishers.

Alarcos Llorach, E. (2000). Gramática de la lengua española. Madrid: Espasa Calpe.

Almela Pérez, R. (2000). ¿Es nosotros el plural de yo? ELUA. Estudios de Lingüística, 14, 9-17.

Bazzanella, C. (2002). The significance of context in comprehension: the 'we case'. Foundations of Science, 7, 239-254.

Benveniste, E. (1971). Problemas de lingüística general. México, D. F.: Siglo XXI.

Blas Arroyo, J. L. (2000). Mire usted Sr. González... Personal deixis in Spanish politicalelectoral debate. Journal of Pragmatics, 32, 1-27.

Borthen, K. y Thomassen, G. (2014). Referential and functional aspects of the Norwegian first person plural vi. En T. S. Pavlidou (Ed.), Constructing Collectivity. 'We' across languages and contexts (pp. 65-82). Philadelphia: John Benjamins Publishing Company.

Brisard, F. (2002). Introduction: The epistemic basis of deixis and reference. En F. Brisard (Ed.), Grounding: The Epistemic Footing of Deixis and Reference (pp. XI-XXXIV). Berlin: Mouton de Gruyter.

Brown, P. y Levinson, S. C. (1987). Politeness: Some universals in language usage. Cambridge: Cambridge University Press.

Bühler, K. (1979). Teoría del lenguaje. Madrid: Alianza Editorial.

Bull, P. y Fetzer, A. (2006). Who are we and who are you? The strategic use of forms of address in political interviews. Text and Talk, 26(1), 1-35.

Cuervo, J. R. (1998) Diccionario de construcción y régimen de la lengua castellana. Barcelona: Herder.

De Cock, B. (2009). Funciones pragmáticas de la referencia de persona en el lenguaje coloquial y en el discurso político. Oralia, 12, 247-266.

De Cock, B. (2011). Why we can be you: The use of 1st person plural forms with hearer reference in English and Spanish. Journal of Pragmatics, 43, 2762-2775.

De Cock, B. (2014). Profiling Discourse Participants: Forms and functions in Spanish conversation and debates. Philadelphia: John Benjamins Publishing Company.

Duszak, A. (2002). Us and Others: An introduction. En A. Duszak (Ed.), Us and others: social identities across languages, discourses and cultures (pp. 1-28). Philadelphia: John Benjamins Publishing Company.

Escavy Zamora, R. (2011). Pragmática y subjetividad lingüística. Murcia: Editum, Ediciones de la Universidad de Murcia. 
Fernández Soriano, O. (1999). El pronombre personal. Formas y distribuciones. Pronombres átonos y tónicos. En I. Bosque y V. Demonte (Eds.), Gramática Descriptiva de la Lengua Española (Vol. 1) (pp. 1209-1273). Madrid: Espasa Calpe.

Fetzer, A. (2014). "Judge us on what we do": Te strategic use of collective we in British political discourse. En T. S. Pavlidou (Ed.), Constructing Collectivity. 'We' across languages and contexts (pp. 331-350). Philadelphia: John Benjamins Publishing Company.

Fowler, R. y Kress, G. (1983). Lingüística crítica. En R. Fowler, B. Hodge, G. Kress y T. Trew (Eds.), Lenguaje y control (pp. 247-286). México, D. F.: Fondo de Cultura Económica.

García Negroni, M. M. (2008). Subjetividad y discurso científico-académico. Acerca de algunas manifestaciones de la subjetividad en el artículo de investigación en español. Revista Signos, 41(66), 5-31.

Gelabert-Desnoyer, J. J. (2006). Registro y funciones de "nosotros" en el discurso parlamentario español contemporáneo. Linred: lingüística en la Red, 4, 1-21.

Gili Gaya, S. (1946). Nos-otros, vos-otros. Revista de filología española, 30, 108-117.

Harré, R. (1982). El ser social. Una teoría para la psicología social. Madrid: Alianza Editorial.

Harré, R. (2014). Preface. En T. S. Pavlidou (Ed.), Constructing Collectivity. 'We' across languages and contexts (pp. IX-X). Philadelphia: John Benjamins Publishing Company.

Haverkate, H. (1994). La cortesía verbal. Estudio pragmalingüístico. Madrid: Gredos.

Helmbrecht, J. (2002). Grammar and function of we. En A. Duszak (Ed.), Us and others: social identities across languages, discourses and cultures (pp. 31-49). Philadelphia: John Benjamins Publishing Company.

Jakobson, R. (1975). Los conmutadores, las categorías verbales y el verbo ruso. En Ensayos de lingüística general (pp. 307-332). Barcelona: Seix Barral.

Jespersen, O. (1922). Language: Its Nature, Development and Origin. London: George Allen \& Unwin Ltd.

Jespersen, O. (1975). La filosofía de la gramática. Barcelona: Anagrama.

Juan XXIII. (1961). Discurso del Santo Padre Juan XXIII al cuerpo diplomático durante el homenaje por su octogésimo aniversario. Recuperado de https://w2.vatican.va/content/ john-xxiii/es/speeches/1961/documents/hf_j-xxiii_spe_19611103_corpo-diplomatico.html

Kerbrat-Orecchioni, C. (1997). La enunciación. De la subjetividad en el lenguaje. Buenos Aires: Edicial.

Lenz, R. (1925). La oración y sus partes. Estudios de gramática general y castellana. Madrid: Centro de Estudios Históricos.

Manuel Oloume, F. (2015). Objetividad/subjetividad: marcas gramaticales y léxicas en la prosa académica en cuestiones de lengua (español y francés) (Tesis doctoral). Universidad de Salamanca, Salamanca, España.

Nowikow, W. (1994). Sobre la pluralización de personas gramaticales en las lenguas románicas: 'nos', 'vos' - 'nos alteros', 'vos alteros'. Anuario de Lingüística Hispánica, $10,283-300$. 
Pavlidou, T. S. (2014). Constructing collectivity with 'we': An introduction. En T. S. Pavlidou (Ed.), Constructing Collectivity. 'We' across languages and contexts (pp. 1-19). Philadelphia: John Benjamins Publishing Company.

Pennebaker, J. (2011). The Secret Life of Pronouns. What Our Words Say About Us. New York: Bloomsbury Press.

Petersoo, P. (2007). What does 'we' mean? National deixis in the media. Journal of Language and Politics, 6(3), 419-436.

Real Academia Española. (1973). Esbozo de una nueva gramática de la lengua española. Madrid: Espasa-Calpe.

Real Academia Española. (2010). Nueva gramática de la lengua española. Manual. Madrid: Espasa.

Rivarola, J. L. (1984). ¿Quién es nosotros? ELUA. Estudios de Lingüística, 2, 201-206.

Serrano, M. J. (2013). De la cognición al discurso: el efecto de la prominencia cognitiva y la informatividad textual en el estudio de la variación de los sujetos pronominales. ELUA. Estudios de Lingüística, 27, 275-299.

Serrano, M. J. y Aijón Oliva, M. A. (2013). Seguimos con la actualidad... The first-person plural nosotros 'we' across Spanish media genres. Discourse \& Communication, 7(4) 409-433.

Scheibman, J. (2002). Point of View and Grammar: Structural patterns of subjectivity in American English conversation. Philadelphia: John Benjamins Publishing Company.

Spitzer, L. (1947). Vosotros. Revista de Filología Española, 31, 170-175.

Van Dijk, T. (2006). Ideología. Una aproximación multidisciplinar. Barcelona: Gedisa.

Vigara Tauste, A. M. (2000). Sobre deíxis coloquial. CLAC. Círculo de lingüística aplicada a la comunicación, 1, 95-117.

Wieczorek, A. E. (2013). The Foundations of Clusivity. En A. E. Wieczorek (Ed.), Clusivity: A New Approach to Association and Dissociation in Political Discourse (pp. 1-18). Newcastle: Cambridge Scholars Publishing.

Zupnik, Y. J. (1994). A pragmatic analysis of the use of person deixis in political discourse. Journal of Pragmatics, 21, 339-383. 
